\title{
Building Synergy - An Introduction to the Inaugural Issue
}

\author{
D.H. Steve Zou, Ph. D., P. Eng. \\ Editor-in-Chief
}

\section{Welcome}

It is my great pleasure to welcome you to the inaugural issue of The International Journal of Geohazards and Environment (IJGE). The purpose of this journal is to provide an international open forum for researchers and practitioners to publish scholarly and high quality original papers, state-ofthe-art reviews and case studies on a wide range of topics relevant to geological and geotechnical hazards. These hazards may include natural disasters, such as, landslides, debris flows, earthquakes and sinkholes, and ground instabilities associated with human activities, such as, slope failure in open pit mining and transportation infrastructures, foundation failure in geotechnical construction, subsidence caused by subsurface excavation and rock burst in underground mining. Environmental issues associated with these hazards are also within the scope of this journal. The intension is to provide everyone involved in these fields an opportunity to share findings from their work and exchange ideas in tackling the associated problems.

It all started with conversations with peers during international conferences dated back a decade ago, when we noticed that there had not been an international journal dedicated to covering the wide range of aforementioned topics in geohazards. The idea of establishing such a journal grew stronger in recent years during which I had opportunities to work with colleagues in other fields, such as debris flows and earthquakes, when I noticed tremendous similarities with rock engineering in many cases. After consultation with many colleagues and a busy period of preparation over the past year, this multidisciplinary journal has finally debuted today, covering the areas of natural disasters and ground instability induced by human activities.

Keywords: landslide, debris flow, earthquake, rock mechanics, ground stability, novel research

\section{Acknowledgment}

I must confess, however, that I quickly learned that establishing a reputable international journal was not a simple or casual undertaking. There have been many hurdles to overcome. The existence of IJGE today is attributed to many people involved during the process. Consequently, there are several people that should be acknowledged and thanked for their encouragement, support and help, which were extended to me in many different ways.

Among them, I wish to acknowledge the following people: Dr. C.O. Brawner, the
Honorary Editor, for his belief in the significance of this endeavour and his advice; Geoffrey Brown, Digital Scholarship Librarian, for his guidance in many aspects concerning open journals; Susan Harris, Library Specialist, for her assistance in the open journal system; Dr. Josh Leon, Dean of the Faculty of Engineering at Dalhousie University and Professor R.Q. Huang, Director of the State Key Laboratory of Geohazards Prevention and Geoenvironment Protection, for their part of support; Dr. Y.Y. Zhu and Professor J.L. Cheng, for their participation during the preparation process; and 
the IJGE Editorial Board members who have helped in making the journal a reality.

I especially wish to recognize and thank our authors for their contributions by submitting their manuscripts, their excellent scholarship, and their belief in the significance of this new journal. I also wish to thank our reviewers for their valuable time and input in the review process.

\section{Searching for common grounds between Natural Disasters and Excavation-Induced Ground Instabilities}

At this moment, I would like to toss a few points related to the topics of the journal. Hopefully, they will inspire some creative minds and generate some new ideas, thus opening novel research windows, or simply sparking some discussions in the overall area of geohazards.

My work in the earlier years over the past 30 years was mostly focused on rock mechanics and ground stability control in the mining industry. This would require knowledge and understanding of stress distribution in the ground, rock mass failure mechanisms, effects of excavation and support methods on ground stability when failure is anticipated. Optimized design in practice often calls for changing some controllable parameters to reduce the risk of ground failure and to achieve the required stability. My work in the later years took me beyond the engineering field and exposed me to other areas, such as, debris flows, landslides and earthquakes.

\section{Landslides, Slope Failure and Debris Flows}

Several years ago, I was first exposed to the debris flows in western China as part of my research collaboration with Chengdu Institute of Mountain Hazards and Environment. My visit to the Dongchuang Debris Flow Observation and Research Station (DDFORS) has deeply impressed me. The scale of debris flows and the area affected in that one gulley are beyond what one can image in the engineering field (Fig. 1). Conversations with the late Professor Z.C. Kang, former Director of DDFORS, and Professor P. Cui, Director of the Key Laboratory of Mountain Environment Evolution and its Regulation of
Chinese Academy of Science, certainly opened my eyes to the geohazards field. The debris flows were disastrous in the peak seasons and have been continuously changing the landscape in the area for several decades, and will continue for many more decades to come in that area. Similar cases exist in many other countries around the world.

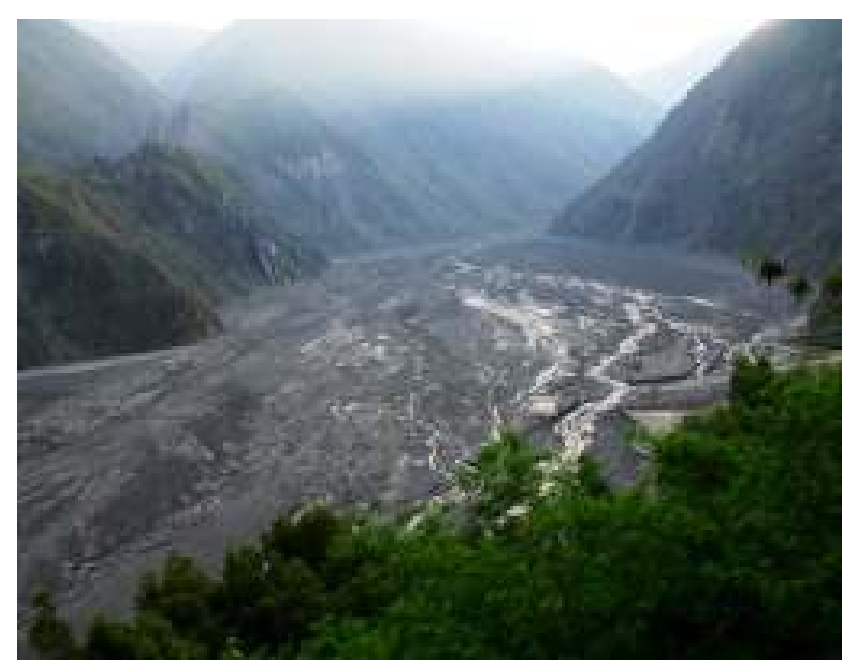

Fig. 1 Debris flows in Dongchuang, Western China $(>300 \mathrm{~m}$ wide in the center)

In examining the nature of debris flows, we can identify two important components: sources of a large amount of water and loose geo-materials. The latter comes from the eroded surface materials and fresh landslides. In fact, evidence of historical landslides in various scales is visible almost everywhere in the mountainous areas (Fig. 2). These landslides may become the sources of debris flow in a gulley or exist as stand-alone hazards.

The mudflow (Fig. 3), as it is called, occurred on March 22, 2014 east of Oso, Washington, United States, made the global news as geohazards. It was reportedly (Wikipedia online, 2014) the result of collapse of an unstable hill and covered an area of approximately $2.6 \mathrm{~km}^{2}$ and killed 43 people. There are many technical reports on this event; one triggering factor seemed to be the erosion of the hill toe due to the river running along the hillside. 


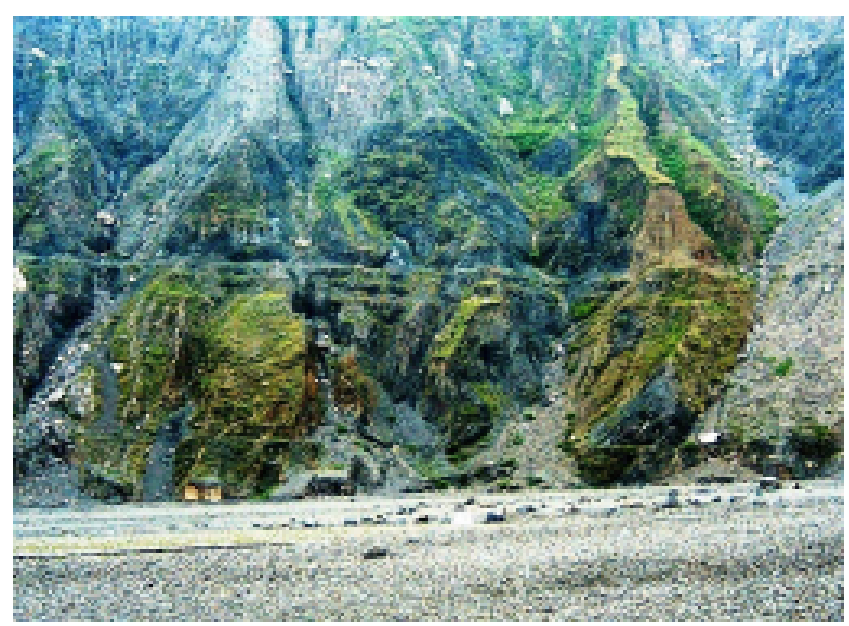

Fig. 2 Historical large landslides, Western China (far ground $>1000$ m away)

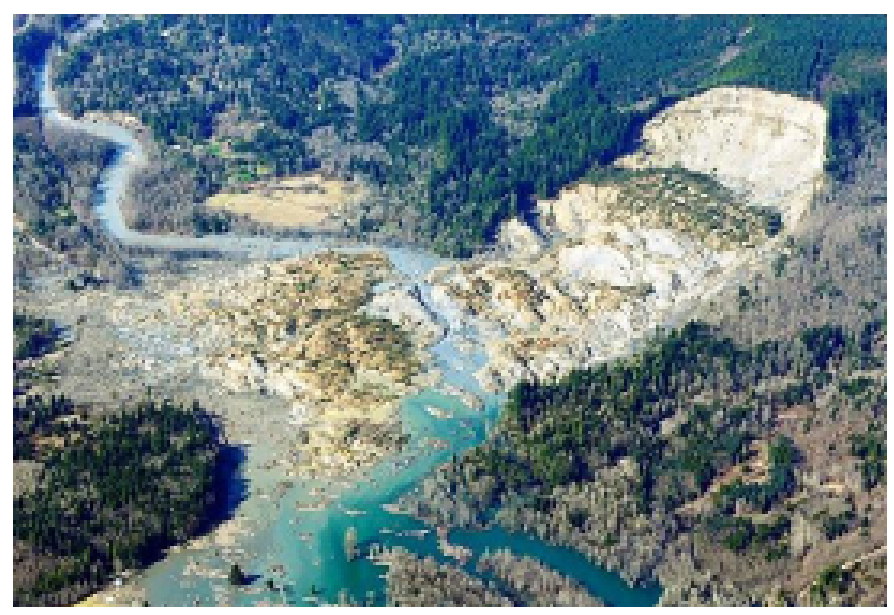

Fig. 3 Oso Mudslide, Washington, USA (Google online image)

The primary and obvious question that comes to the mind of any engineer working on slope stability in open pit mining, or geotechnical engineering would be: what do the natural landslides and the slope failure in geotechnical engineering have in common? Although the controlling factors may be different in each case, the failure mechanisms seem to be the same. There must be something which can be shared by those involved in the two areas.

\section{Earthquakes and Rockbursts}

The Great Earthquake (Wikipedia online 2008) occurred on May 12, 2008 in Wenchuan County, Sichuan Province, China shocked the world. I had an opportunity to investigate the disaster-affected area one month later with a research team. What I saw on the surface was beyond one's imagination: mountain surfaces collapsed in various scales and the scars were visible everywhere over $100 \mathrm{~km}$ distance. There are numerous technical reports and research publications following this disaster. One dominant hypothesis of this disaster was associated with thrust fault movement in the earth crust across the Longmen Shan Fault system. However, the epicentre presented another very interesting scene (Fig 4): millions of tons of debris were projected for more than one $\mathrm{km}$ distance away, seemingly in an action similar to a burst or explosion, and as a result buried a village on its way (Fig 5).

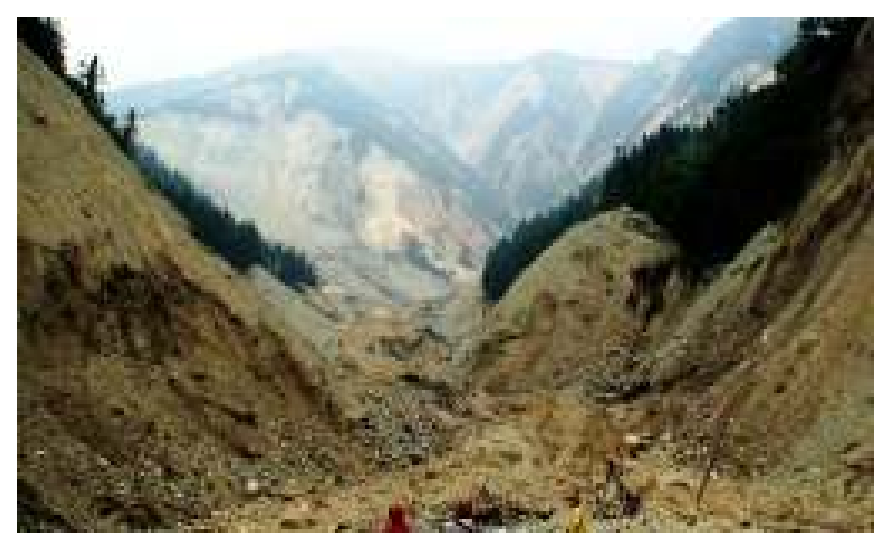

Fig. 4 Wenchuan Earthquake epicentre (far ground, looking up the hill),

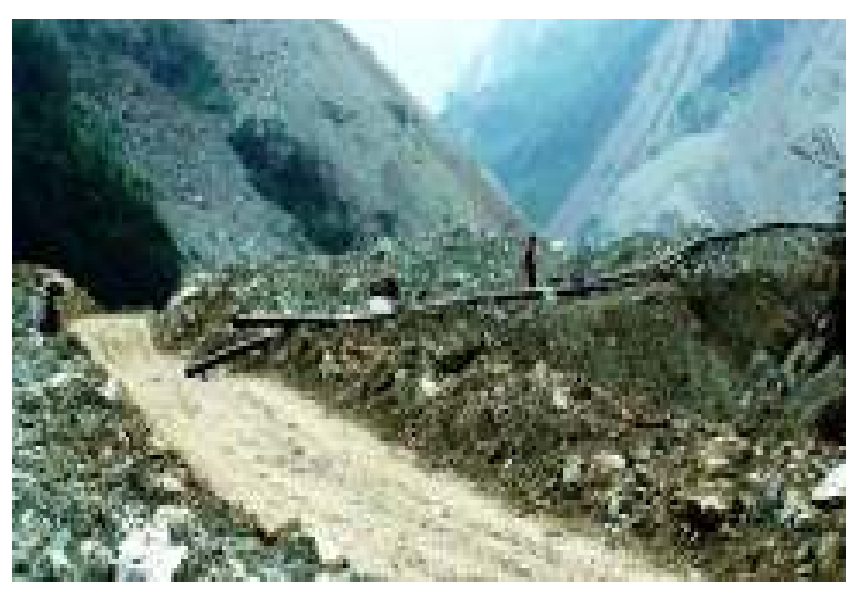

Fig. 5 Debris (fore ground) below the epicentre stretching $>1 \mathrm{~km}$ distance (looking down the hill) 
This prompted me to think about rock bursts that occur in underground mines. In general, we classify rock bursts in two categories: fault slip burst and strain burst. Fault slip rock burst is very similar to earthquakes associated with fault movement. Strain burst is the result of sudden release of strain energy in highly stressed ground when it fails. Then the question arises: do earthquakes and rock bursts have anything in common? Can lessons learned in one area be used in another area?

\section{Subsidence and Sinkholes}

On March 1, 2013 it was reported (CNN, 2013) that a sinkhole swallowed a Florida man when it opened suddenly beneath his bedroom in Tampa, Florida. The hole was reportedly about $20^{\prime}$ to 30 ' in diameter and 30' deep. I did a quick search online and found many research reports, which revealed that sinkholes were very common in the State of Florida because of its geological ground conditions, and that they exist in a number of other states as well. In the situation of a sinkhole, a void is developed in the bedrock over time. If the overburden materials above the void are strong, it may be able to hold the ground for some time. Otherwise, the ground may fall into the hole. The effect on the surface will depend on the size of the hole and material properties. In many cases, this is closely associated with groundwater seepage.

Working in mining engineering, we have become familiar with ground subsidence caused by underground excavations. Ground sunk in abandoned mine sites have been widely reported. Rock strata above mined areas, such as in room and pillar mining and longwall coal mining, may fracture and break under the stress in the ground. This process develops upwards and may eventually reach the surface, depending on the mining depth and height, rock mass properties and some other factors. Although natural sinkholes and mining-induced subsidence are the result of completely different causes, the failure mechanisms are again remarkably similar. The question comes again: can the preventative measures developed in one area be used in another area? Can the field monitoring methods and detection technologies be used in both areas?

\section{Building Synergies}

It has become clear to me that whether we are tackling the natural disasters or dealing with the excavation-induced ground instabilities, there are common grounds and that many aspects could be learned from these two broad fields. Consequently, this journal, the first of its kind, aims to bring together the researchers and practitioners from these two fields. Once we understand the differences and similarities, we can build synergies in tackling these problems.

\section{Novel Ideas}

Another purpose of this journal is to provide a platform for researchers to present novel ideas in a related area and to have open discussions on non-conventional concepts. There has been significant volume of research dedicated toward harvesting tidal energy for power generation in recent years. In parallel, one, therefore, ponders whether there would be any way that one could utilize the mega power of natural disasters to one's advantage.

As an example, the flow of large debris generates tremendous power; it can carry housesized boulders several kilometres away (Fig. 6). It has the power to change the landscape on the surface (Fig. 1); this power is destructive, as we know. As a topic for discussion in this open forum, can we harness this power to benefit the mankind?

During my field trips to western China, I also noticed some very interesting phenomena, which looked natural at the first glance but had farreaching meanings. Some villages were built on flat grounds, the sediments created by ancient debris flows, with wide-spread farm land (Fig. 7). The logical question is then: why can't we take advantage of the power of debris flows to reshape the land in the form we need through engineering means? For instance, by creating new flat terrains in the mountain areas, where flat ground is extremely limited?

With our knowledge and wisdom, we, the humans have made outstanding progress in many 
areas in the world. We can and should be able to make constructive alterations to the nature so that the earth becomes a better place for us to live in the future. Let us use our wisdom and capacity to capture the mighty power of the nature, by following the course of the nature, and harness it to reform the nature to better benefit the mankind! May these simple examples and ideas inspire much subsequent thought and scholarship.

The Editorial Board and I very much look forward to seeing new research outcomes.

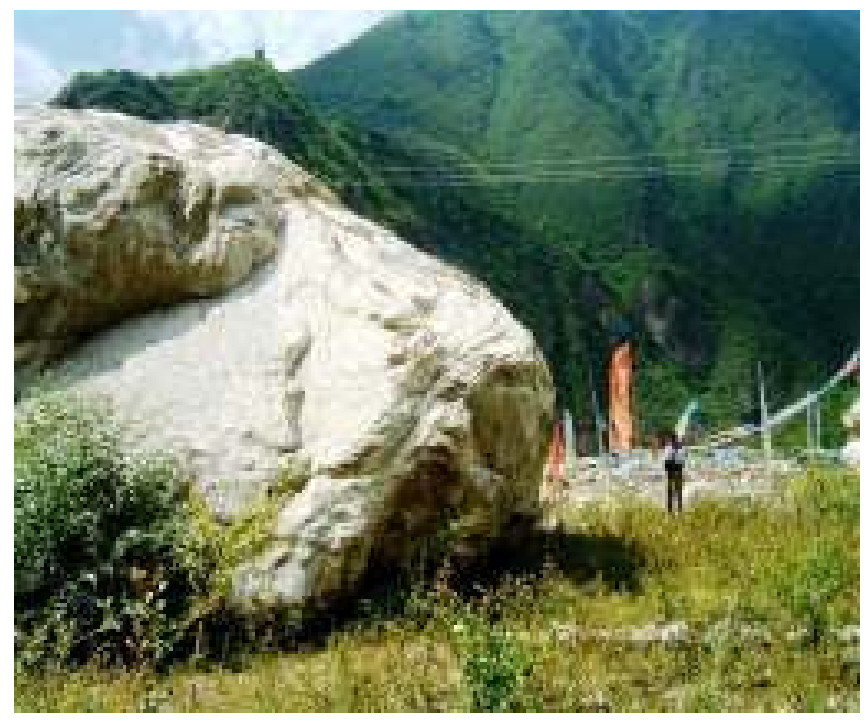

Fig. 6 House-size boulder carried here by debris flows

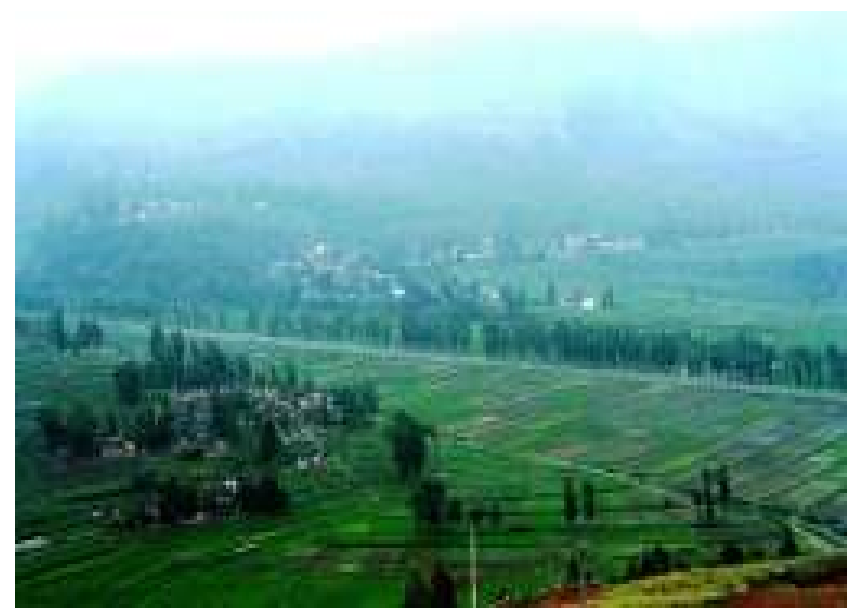

Fig. 7 A typical village built on sediment created by ancient debris flows
Halifax, Nova Scotia, Canada

March, 2015

\section{References}

CNN report, 2013. A loud crash, then nothing: Sinkhole swallows Florida man. http://www.cnn.com/2013/03/01/us/floridasinkhole/index.html.

Wikipedia online, 2008. 2008 Sichuan earthquake.

http://en.wikipedia.org/wiki/2008_Sichuan_e arthquake.

Wikipedia online, 2014. Oso mudslide. http://en.wikipedia.org/wiki/2014_Oso_muds lide\#Overview. 